\title{
Faculty Development Prior to an International Cohort
}

\author{
Diane F. Hunker1 ${ }^{*}$, Debra M. Wolf ${ }^{1}$, Kathleen C. Spadaro ${ }^{1}$, Huixin Wu ${ }^{2}$ \\ ${ }^{1}$ Chatham University, Pittsburgh, PA, USA \\ ${ }^{2}$ Davis \& Elkins College, Elkins, WV, USA \\ Email: ^dhunker@chatham.edu,dwolf@chatham.edu, kspadaro@chatham.edu,wuh@dewv.edu
}

How to cite this paper: Hunker, D. F., Wolf, D. M., Spadaro, K. C., \& Wu, H. X. (2021). Faculty Development Prior to an International Cohort. Open Journal of Social Sciences, 9, 165-172.

https://doi.org/10.4236/jss.2021.93011

Received: February 18, 2021

Accepted: March 14, 2021

Published: March 17, 2021

Copyright ( 2021 by author(s) and Scientific Research Publishing Inc. This work is licensed under the Creative Commons Attribution International License (CC BY 4.0).

http://creativecommons.org/licenses/by/4.0/

\begin{abstract}
Universities enroll international students and often faculty receives minimal development prior to their arrival. An anonymous electronic survey was used to collect data from faculty and staff on their preparations for international students. Findings suggested formal instruction on how to educate international students, including tips for ESL challenges, might yield the most significant benefit for faculty ultimately adding to the success of the students. Faculty development prior to student arrival appears to be important, especially for those intending to interact with international students on a regular basis. Best practices can be gleaned from their shared experiences.
\end{abstract}

\section{Keywords}

International Students, Faculty Development, Study Abroad, ESL Students

\section{Introduction}

To expand their academic capacity, university administrators often network with foreign universities to develop study abroad programs (Spadaro et al., 2017). Typically, faculty is not part of the preliminary discussions or the contract process. Once a formal agreement is finalized, the host university opens enrollment to the international students. At times, little formal preparation is provided to the faculty and staff as to how to instruct, host and interact with international students.

Prior authors have described the role of US faculty teaching abroad and suggested strategies for a successful transition (Gopal, 2011; Hulstrand, 2012). With the globalization of higher education and faculty teaching at branch campuses across the globe for either short- or long-term study abroad programs, faculty need to be prepared for this new global role. However, the focus of this pilot 
study was the reverse scenario with an international cohort coming to a US campus. Other studies have focused on international students' learning practices and experiences while studying abroad in the US which offered insights and recommendations for faculty based on the students' feedback (Heng, 2018; Palmer et al., 2019).

Conversely, few authors have shared the preparation needed for faculty and staff. Faculty at a Texas school of nursing shared their practices of preparing students, faculty and staff for the arrival of a cohort of graduate nursing students from India. The authors indicated that increasing the faculty's knowledge regarding Indian culture and healthcare systems seemed to be of critical importance. Additionally, selected faculty were involved in developing a "bridge program" for the students prior to beginning the graduate program (Robinson et al., 2006). Spadaro et al. (2017) provided a high-level overview of the steps involved in preparing for a student cohort from China but did not provide in depth detail regarding the specific methods or effectiveness of faculty and staff preparation.

Other authors have described the needs of international students and how best to educate them (Ryan et al., 1998; Del Fabbro et al., 2015). Findings from a study involving Taiwanese undergraduate nursing students detailed the preparation needed by the students, yet specific details regarding faculty preparation and outcomes were only minimally provided (Ryan et al., 1998). Results from a participatory action research (PAR) study that examined the teaching of international nursing students mixed with domestic students were also reported. In this study, faculty self-reflections were explored; themes such as recognizing and respecting diversity and developing and acknowledging teaching capabilities emerged regarding the faculty experience of teaching in a diverse classroom (Del Fabbro et al., 2015).

While some may posit that faculty development may not be required, nursing faculty at a small university in the mid-Atlantic region of the United States (US) recognized the need. Upon review of the literature, the faculty discovered research findings involving faculty and staff's preparation prior to the arrival of international nursing students staying for an extended program was limited and dated. More specifically, there was a paucity of research suggesting best practices for faculty development in preparation for a year long, international cohort. This gap in the literature led to a pilot study that explored how to prepare faculty and staff for an international cohort of graduate nursing students.

The purpose of this article is to share the findings of a pilot study that addressed the research question "What were the needs of faculty and staff in preparing and supporting international Chinese students? This study was initiated due to the university hosting a cohort of professional, baccalaureate-prepared nurses from China for a one-year study abroad program culminating in an MSN degree. Prior to students' arrival, faculty had six months to 1) understand the learning needs of international students, 2) convert the online MSN program into an on-ground program, 3) interview and select the international students based on a predefined set of admission criteria, and 4) work jointly with the Of- 
fice of International Affairs, Student Affairs, and Residence Life to plan Englishas-a-Second Language (ESL) support, cultural activities, and living arrangements. These tasks were completed in addition to the regular faculty workload. Prior to this program, faculty had no prior experience with working with international nursing students.

The intent of the survey was to guide future faculty development. Data were also collected to identify the experience of working with international students so that a collection of best practices could be compiled for future use, if desired. Several teaching strategies faculty used to improve interactions with the international students were also identified.

\section{Method}

The setting for this pilot study was a nursing department in a small, private, midAtlantic university that traditionally only offered online courses in accredited RN-to-Bachelor of Science in Nursing (BSN), Master of Science in Nursing (MSN), and post-master's Doctor of Nursing Practice (DNP) programs. The study was approved by the university Institutional Review Board. The research team consisted of the Nursing Program Director, the Assistant Program Director, the MSN Program Coordinator, and a nursing faculty member that taught in the International MSN Program.

A 17-item survey was developed, reviewed and approved by the investigators for the purpose of this pilot study only. The survey consisted of one demographic item followed by a variety of question formats: Likert response, multiple choice with explanation, yes/no with explanation and open-ended questions. Survey reliability and validity were not established prior to use.

Two weeks after the international students completed their one-year program, the investigator-developed electronic survey using Qualtrics ${ }^{\mathrm{TM}}$ was emailed to approximately 80 faculty and campus staff that could have interacted with the students during the one-year period. The email, which also included details on the purpose of the survey, instructions for completion and informed consent, was sent via the university email system by the School of Health Sciences dean. The participant group included nursing faculty, and staff from various departments such as information technology, library, student affairs, dietary, security, transportation, student learning support and international affairs. Voluntary response to the survey indicated consent, and personal identifiers were not collected.

The initial demographic question asked if they were faculty or staff. The questions on the survey specific to the research question were: 1) "Did you prepare? If so, was it helpful?"; 2) "Once you interacted with the Chinese students, do you believe you were prepared?”; 3) "Reflecting back on your experiences what needs have you identified that would better prepare you for the next cohort of Chinese

students? Please explain"; and 4) "How would you recommend future staff/faculty be prepared to interact with Chinese students?" 
For question one on the electronic survey, respondents selected either 'Yes" they prepared or "No" they did not prepare. If they selected "Yes", they were asked to explain their response further by typing into a free text comment section. They were then asked if the preparation was helpful, "Yes" or "No", and again asked to explain their response via free text. For question two, the option for response was "Yes" or "No" with no free text offered. Questions three and four were responded to via free text only and no concrete data were collected.

Additionally, open-ended questions about the experience of interacting with the students were also included. More specifically, faculty were invited to share more information on the: 1) types of interactions, 2) challenges or obstacles faced throughout the year, 3) rewarding aspects of the experiences, 4) how interactions changed over time, and 5) anything else they wanted to share about teaching in the study abroad program. This data on the experience of interacting with the students were not evaluated for the purpose of the research question, but rather reviewed for the purposes of identifying lessons learned and best practices for future use. The university and the sending institution in China had already planned to repeat the program for subsequent years.

The survey was open for two weeks to allow for participation with one reminder email sent. Once the survey was closed, all four investigators reviewed the data collected. Concrete variables were calculated as a percentage and numeric total of "Yes" and "No responses. Free text responses from questions 1, 3 and 4 described above were reviewed and discussed. Given the small sample size, no further statistical analyses were completed, and formal qualitative analysis methods were not applied.

\section{Results}

A total of 80 faculty and staff received the email. However, many of the staff in auxiliary departments (e.g. dietary, transportation, security) did not access email regularly or had minimal to no encounters with the students, thus reducing the number of expected responses. A total of 18 responses were received ( 7 faculty and 11 staff). No further demographics or specific staff titles were collected. The amount of time the respondents interacted with the students varied greatly depending on their role. Varying types of interactions with the Chinese students were reported, such as: "clinical coordination", "ESL support", "teaching", "welcome meeting", "graduation ceremony", "technology related topics", "Reception", "managed their housing", "guest lecture", and "plagiarism presentation and in the library".

When asked if they prepared for their interaction with the Chinese students (question one), ten respondents reported they did prepare and eight reported they did not. Some of the preparation activities shared included: "reviewing Chinese history, culture or nursing in China, teaching strategies for ESL students", "reviewing background information on the MSN program", and other general activities related to preparing course activities and lectures (which would 
be similar to activities preparing for domestic students). The ten respondents who found it was helpful to prepare ahead of time shared detailed comments including: "definitely", "it was helpful initially... but then I got to know them personally", "helped me prepare what I was going to say to the students and think about the most basic language to use to avoid potential misunderstandings", and "I collected information from my staff in order to learn about what the students need and what I need to find out from them". None of the respondents who said the preparation was not helpful provided any detailed explanation. In total, 15 of the 18 respondents (83\%) believed they were prepared to interact with the students (question two).

Reflecting on their experiences, faculty and staff shared rich descriptions of activities that could have been offered to help them better interact with the Chinese students (question three). Responses included: "English as a second language teaching strategies", "understand their background further and what outcomes they were expecting", "more cultural knowledge", "suggestions on how to get the students comfortable in the class", and "a description of their healthcare environment and cultural indicators".

When asked what recommendations they had for future faculty or staff development (question four), the respondents shared the following: "provide networking experiences with others that typically work with ESL students to provide best practices", "know the culture and understand ESL", "realize the difference in learning needs and implement different teaching strategies to help them learn effectively", "...use communication strategies to arrive at a mutual understanding such as asking clarification questions, asking comprehension questions in a friendly way, wait longer for the students to answer, repeat and paraphrase", "just engage with them...", "do not hesitate to repeat yourself even if it seems redundant. Sometimes they do not understand but agree just to not appear rude", "a smile goes a long way", and "have Academic Affairs offer a workshop on working with international students".

\section{Discussion}

Given the responses to the research questions, general preparation for an international cohort of nursing students appeared to be beneficial for faculty and staff intended to interact with them on a regular basis. Understanding the students' culture and nursing as a profession in China was reported to be beneficial. Formal instruction on how to educate and interact with international students, specifically those with ESL, might yield the most significant benefit and was suggested to offer as a formal workshop.

Respondents had the opportunity to also share some other content related to the interactions with the international students over the course of the one-year study abroad program. While not reported for the purpose of the study, most respondents did share their experience interacting with the students was positive while no respondents shared anything negative about the experience. Some of 
the terms used to describe the students included: grateful, eager, kind, positive, pleasant, polite, attentive, interested, receptive, courteous, cooperative, and welcoming. Not surprisingly, it was reported that the students lacked confidence during their earlier class discussions. Their ability to speak English was not strong nor was their understanding of the content in the academic program. Over the course of the year, their language skills improved greatly as did their confidence. All respondents working with the students regularly noted a significant difference in the students' personal level of confidence between the first and third semesters.

A teaching strategy shared to combat the lack of confidence was calling on individual students to participate; otherwise, the typical practice of the students was to allow the most confident and strongest English speaker to answer all the questions. Additionally, respondents shared that having a more relaxed, less formal atmosphere allowed for the students to be more comfortable in their new setting. Smiling frequently and engaging them in fun learning activities was reported to be an effective interaction technique when engaging with the students.

The small sample size and the inconsistent rates of interacting with the students during the year long program prohibit the findings of this pilot study from being generalizable.

While this study abroad program was unique in that the students were living as a cohort for a year at the host site and had the opportunity to become comfortable over time, future studies regarding how to best prepare for an international cohort may focus on study abroad programs of varying lengths and involving students from multiple countries. An interesting future study might include faculty development on teaching strategies that yield the best student outcomes and foster optimal learning for international students over time. Additionally, the focus of this study abroad program was aimed at professional nurses from China. As such, responses were aimed at practices geared toward nursing education and healthcare. As a result, information on faculty development prior to students' arrival and experiences shared by faculty were reviewed to elucidate teaching-learning practices aimed at nursing education. However, the recommendations shared can easily transfer to other disciplines, and preparation steps taken can be inclusive of any discipline specific content.

\section{Implications for Practice}

Based on the findings and experiences of faculty several implications for practice can be made. A formal workshop to prepare faculty and staff prior to the arrival of an international cohort may assist universities preparing to host international students for a long-term study abroad program. Agenda topics for the workshop may include communication strategies, culture and history of the foreign country, practices needed to engage and interact with ESL students, and optimal teaching practices needed to promote comfort, confidence and learning.

Engaging an ESL professional to assist faculty with their initial interactions 
with students would help reduce anxiety for all and provide an opportunity for clear exchange of communication. Finally, the early identification and use of electronic tools for faculty to assist with translation of terminology would provide more confidence in one's ability to communicate with international students. Prior authors have also shared strategies for teaching ESL nursing students (Choi, 2005; Olsen, 2012; Hansen \& Beaver, 2012; Rao, 2006) and their findings would be useful for the development of the workshop.

\section{Conclusion}

Universities across the US are inviting international students to study abroad for an extended period. Universities rely on faculty and staff to ensure the success of the program yet recent studies regarding the faculty development and staff preparation needed prior to hosting international students has been limited. Best practices for preparation are needed in the literature and procedures for formal programming and workshops may be beneficial. This pilot study began to share what is known about preparing for an international student cohort and offered suggestions for future host sites. While not having a large sample size or consistent numbers of interactions between the faculty/staff and the students, the rich feedback shared of the experiences further supported the faculty development efforts at this host site for future international cohorts; therefore, the pilot study was deemed as beneficial by the investigators and the academic leadership.

\section{Conflicts of Interest}

The authors declare no conflicts of interest regarding the publication of this paper.

\section{References}

Choi, L. L. S. (2005) Literature Review: Issues Surrounding Education of English-as-aSecond Language (ESL) Nursing Students. Journal of Transcultural Nursing, 16, 263-268. https://doi.org/10.1177/1043659605274966

Del Fabbro, L., Mitchell, C., \& Shaw, J. (2015). Learning among Nursing Faculty: Insights from a Participatory Action Research Project about Teaching International Students. Journal of Nursing Education, 54, 153-158. https://doi.org/10.3928/01484834-20150218-12

Gopal, A. (2011). Internationalization of Higher Education: Preparing Faculty to Teach Cross-Culturally. International Journal of Teaching and Learning in Higher Education, 23, 373-381. https://eric.ed.gov/contentdelivery/servlet/ERICServlet?accno=EJ946163

Hansen, E., Beaver, S. (2012). Faculty Support for ESL Nursing Students: Action Plan for Success. Nurse Education Perspectives, 33, 246-250.

https://doi.org/10.5480/1536-5026-33.4.246

Heng, T. T. (2018). Different Is Not Deficient: Contradicting Stereotypes of Chinese International Students in US Higher Education. Studies in Higher Education, 43, 22-36. https://doi.org/10.1080/03075079.2016.1152466

Hulstrand, J. (2012). Preparing Faculty to Teach Abroad: Lessons Learned. International Educator, 40. https://eric.ed.gov/contentdelivery/servlet/ERICServlet?accno=EJ946163 
Olsen, M. A. (2012). English-as a Second Language (ESL) Nursing Student Success: A Critical Review of the Literature. Journal of Cultural Diversity, 19, 26-32.

Palmer, E. A., Zuraikat N., West, E., Calderone, T. L., \& Shanty, J. (2019). The Lived Experience of International Graduate Nursing Students Engaged with the US Educational System. Journal of Professional Nursing, 35, 174-180.

https://doi.org/10.1016/j.profnurs.2018.12.003

Rao, Z. (2006) Understanding Chinese Students' Use of Language Learning Strategies from Cultural and Educational Perspectives. Journal of Multilingual and Multicultural Development, 27, 491-508. https://doi.org/10.2167/jmmd449.1

Robinson, K., Sportsman, S., Eschiti, V. S., Bradshaw, P., \& Boi, T. (2006). Preparing Faculty and Students for an International Nursing Education Experience. The Journal of Continuing Education in Nursing, 37, 21-29.

https://doi.org/10.3928/00220124-20060101-07

Ryan, D., Markowski, K., Ura, D., \& Liu-Chiang, C. (1998). International Nursing Education: Challenges and Strategies for Success. Journal of Professional Nursing, 14, 69-77. https://doi.org/10.1016/S8755-7223(98)80033-1

Spadaro, K. C., Wolf, D., Wu, H., \& Hunker, D. F. (2017). Preparing for an International Student Cohort: Making a Global Impact on Nursing. Nurse Education Today, 57, 88-94. https://doi.org/10.1016/j.nedt.2017.06.014 